\title{
ESTIMATING DESIGN EFFORT NEEDS OF PRODUCT DESIGN PROJECTS USING CAPTURED EXPERT KNOWLEDGE - A PROPOSED METHOD
}

\author{
Holliman, Alexander 'Freddie'; \\ Thomson, Avril; \\ Hird, Abigail \\ University of Strathclyde
}

\begin{abstract}
The quick and accurate estimation of design effort can be make or break for all but the largest of product design consultancies. Traditional design project planning see designers being taken away from the metaphorical drawing board to spend time assessing project briefs and estimating workloads. Typically these designers base these estimates on their tacit knowledge and experience, and for the most part, they are accurate. However, this is time-consuming and therefore (indirectly) costly, as time spent planning, is not time spent designing. Many more sophisticated approaches for estimating design effort have been developed, but many require large bodies of past data and sophisticated analysis, such as artificial neural networks; and others have highly-specific use cases.

This paper proposes a new method to develop a design effort estimation tool for product design consultancies. This method captures the tacit knowledge and experience of design team members and the tool replicates it quickly and effectively; graphically modelling factors that influence design effort needs in product design projects.
\end{abstract}

Keywords: Project management, Design management, Organisation of product development, design effort estimation

\section{Contact:}

Holliman, Alexander 'Freddie'

University of Strathclyde

Department of Design Manufacture and Engineering Management

United Kingdom

alexander.holliman@strath.ac.uk 


\section{INTRODUCTION}

Design effort, the person-hours required to complete design project phases, is the universal resource of product design projects (Salam and Bhuiyan, 2016). The correct management of this resource is the key to the successful completion of a project and ultimately the likelihood of a product design consultancy remaining in operation. Product Design is one of a small collection of industries where one does not know what the outcome of a project will look like from the outset. Unlike New Product Development (NPD) teams within larger organisations, product design agencies can conduct design projects over as many different product types as there are types of objects made by man. The UK design economy, which includes product design, as well as graphic design, digital design, etc. contributed over $£ 85$ billion in gross value add (GVA) (7\% of total) in 2016, employing 1.69 million people in design roles (Benton et al., 2018). This growing economy is characterised as having a "long tail"; one with many small firms, rather than a few large ones. Such firm in the UK have a 60\% survival rate (Office of National Statistics, 2018), which although greater than the average (44\%), is still a $40 \%$ failure rate.

In an industry of predominantly small businesses with a $40 \%$ failure rate, there is a great need for efficient working and efficient project planning. This planning is typically done by designers in these small design teams. Planning is lengthy and time-consuming, preventing designers from doing work towards project completion - productive time is spent planning projects, rather than doing projects, every hour spent planning is an hour that does not directly contribute to the survivability of a business. Adding to this, is the issue that product design agencies, by their nature, tackle a diverse range of projects. These can range from (relatively) simple houseware products, to medical devices, to control systems for complex machinery, to the machinery itself. Such project diversity presents a significant challenge when planning a project. Quick estimation strategies, such as adapting the plans of past projects, will likely not be viable. As such, the planning of these projects will take extra time, as there is limited data or direct experience for comparison. Considering these issues, any means of improving the product design project planning process, either by saving time, or improving accuracy, is vital to the efficiency and livelihood of a product design consultancy.

This paper can be considered to have two parts, the first examines the challenges faced by design effort estimation approaches, and the later proposes the development of a resource forecasting tool development approach a la the DF method, following the CoFIDE method, adopting its changes and improvements.

\section{LITERATURE REVIEW}

\subsection{Why is it so difficult to estimate design effort for product design projects?}

There have been many attempts to develop methods to estimate design effort, which will be covered in the following review. However it is vital to understand that estimating design effort of product design projects is particularly challenging. Initially, one must consider two of the major issues that surround the design process, it is both complex and uncertain. The design process is inherently uncertain (Chalupnik et al., 2009; Dong et al., 2014; Eckert and Clarkson, 2010; Pich et al., 2002); a form of unpredictable problem-solving (Jonassen, 2000) and it is therefore critical that one appreciates the influence uncertainty has over the design process. It is only by doing so, that one can plan product deigns projects, which includes estimating their design effort needs.

The act of designing, in particular the designing of physical products, is a complex one. Some suggest that the inherent uncertainty of the outcome of a product design project is the key to design complexity (Suh, 1999). There are many definitions of complexity, each regarded as either being too vague or too specific to be applicable across all fields (Maurer, 2017), with the categorisation of complexity is something that many have attempted (Lindemann et al., 2009; Musès, 2000; Shah and Runger, 2013), without a clear consensus. From a product design perspective, the design process itself is complex, with many inter-dependent procedures and iterative design activities (Eppinger et al., 1994; Whitney, 1990) to consider a problem, leading to the creation of a variety of different solutions (Harfield, 2007). If there is any complexity within the project, then planning process will be difficult (O’Donovan et al., 2005). 
Of course, the complexity associated with the actual designing of products is not the only issues. There are many factors which can influence the design effort required to complete a design project from a range of different perspectives. In a study considering such factors, Holliman et al (2020) found a range of perspectives from which factors could be considered, with the most common perspectives being that of the product perspective and an organisational perspective. From the product perspective, there are factors such as a products' perceived complexity (Bashir and Thomson, 2001a, 2001b; Shafiee et al., 2019; Tatikonda and Rosenthal, 2000); from an organisational perspective, there are factors such as the process or design method the team uses (Benedetto et al., 2018; Griffin, 1993) and the experience of the design team (Benedetto et al., 2018; Pollmanns et al., 2013).

\subsection{Approaches to estimate design effort in product design}

There have been many attempts to overcome the challenges presented by the inherent complexity and uncertainty of product design projects when estimating the design effort needs of a product design project. Such approaches attempt to create a type of estimation tool, with many considering measurable factors which influence these projects and their design effort needs as the input. In broad terms, such approaches fall into two categories, those that identify factors as part of the tool-creation process; and those which prescribe these factors.

A number of such approaches have been analysed by Holliman et al. (2020) who found that the identification of factors were typically though three means. One approach is through the analysis of historical data, which requires the use of statistical analysis by some means. Some, like Wang et al. (2015) and Pollmanns et al. (2013) use variations on artificial neural networks as part of their analysis. The second engages with experts to collect their insight into factors, typically through interviews or brainstorming, such as those by Benedetto et al. (2018) and Shang \& Yan (2016). The final means of identifying factors is through literature review. Naturally, approaches have also been developed which utilise combinations of these means, and in some cases, such as that of Jaifer et al, (2020), use all three. In all of these cases, there are examples of methods that prescribe factors for all projects, and there are those that identify factors on a case by case basis.

Indeed there are approaches to estimate design effort that do not explicitly use factors in their approach. However, such approaches tend to rely on project stakeholders still having a clear understanding of the design space and what influences it. Similarly with other project duration estimation approaches, such as Agile's "story point" estimation approach (Cohn, 2005) (typically used in software development), with which teams collaboratively rank tasks by duration based on tacit knowledge and experience, abstracting effort into a unit (story point) until work has already started.

\subsection{Using tacit knowledge to estimate design effort}

As alluded to in the introduction, many product design agencies are small so detailed collection and management of past project data may be outside what is feasible. In many cases, these design teams estimate design effort requirements for their projects through the use of experience and tacit knowledge (Brauers and Weber, 1988; Eckert and Clarkson, 2010; Jack, 2013; Serrat et al., 2013). However, although successful, there are some notable limitations. Designers are potentially unable to effectively express justifications for their estimations, resulting in "hunches", which, in turn, can lead to misunderstandings within a design team (Luck, 2013). Additionally, such estimations require the attention of the designers, preventing them (albeit temporarily) from their work, that of designing. Therefore an approach which capitalises on the advantages of using experience and tacit knowledge, which aids in the effective communication of perceptions and does not require designers to be active in the estimation process would be a particular advantage to product design consultancy teams.

\subsubsection{Dataless forecasting}

Dataless Forecasting (DF) (Hird, 2012) is a resource forecasting tool development method created for the NPD teams, which captures and reproduces the tacit knowledge and experience of NPD team managers. This tool has been shown to be accurate, transparent and repeatable when tested in industry. The DF method is a five-step process, outlined in Figure 1. It follows Fisher's Design of Experiments (DoE) (1949) with three main differences: the physical experiments (or simulated) are substituted with the estimations of experts (team managers) about hypothetical scenarios; the objective and measurable 
experimental inputs are replaced with the tacit and subjective knowledge of experts to become the subject of modelling; and results of the analysis are used for prediction, rather than optimisation.

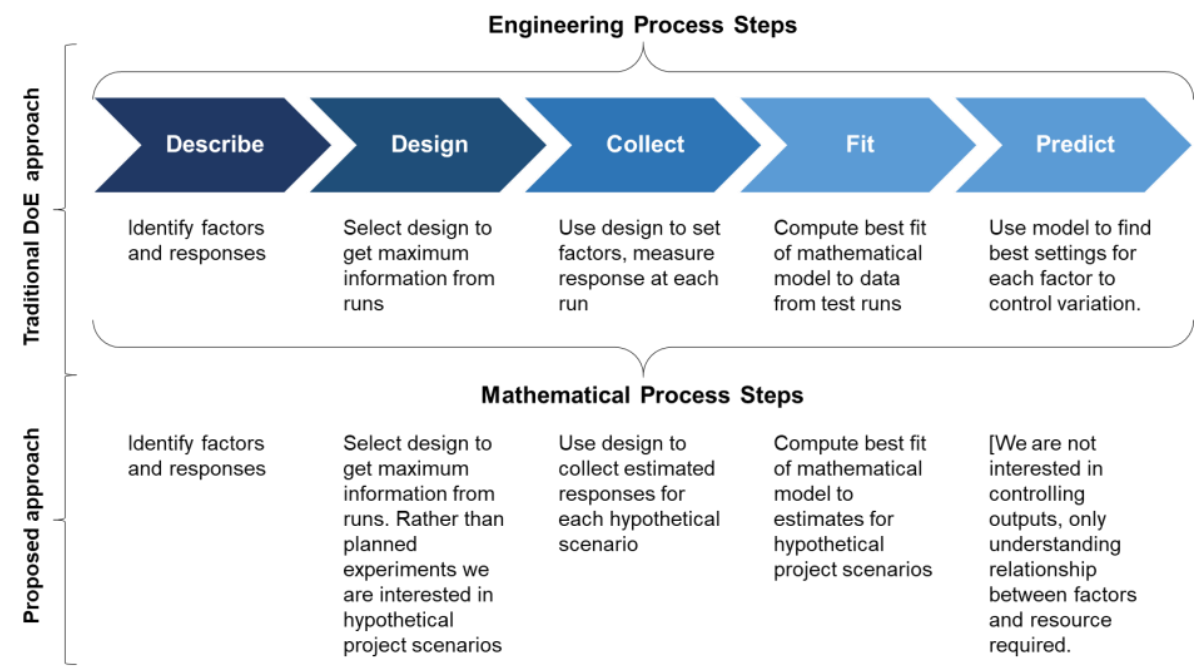

Figure 1. A new product development resource forecasting method. Adapted from Hird (2012)

\subsubsection{COFIDE}

The Collaborative Factor Identification for Design Effort (CoFIDE) method (Holliman, Thomson, Hird, et al., 2020), although building upon DF, is distinct in a number of areas. Firstly, it has been developed for the product design consultancy industry, which has a significantly more diverse range of potential projects, and therefore a more challenging field to understand. Additionally, CoFIDE works collaboratively with all members of a design team, not just the management. This enables the capture of a greater range of insight into the design space and the factors which influence it. Furthermore, the CoFIDE process, shown in Figure 2, characterises the design space by modelling the behaviour of the most influential of these factors using captured expert knowledge. The modelling of these factors grants design teams the opportunity to make possible changes to their environment to improve the positive influences of factors, and the negative influence of others.

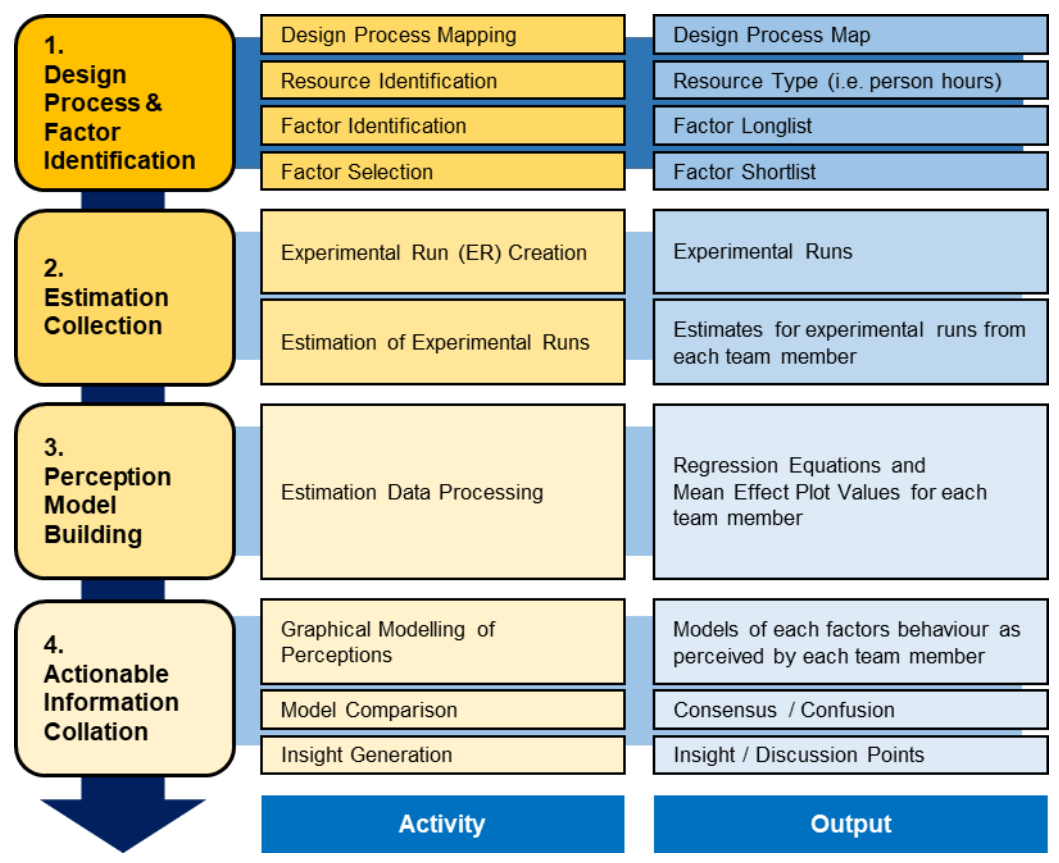

Figure 2. CoFIDE method. Adapted from (Holliman, Thomson, Hird, et al., 2020) 


\subsubsection{CPBS Method}

The Collaborative Project Brief Scorecard (CPBS) Method (Holliman, Thomson and Hird, 2020) is a further development of the CoFIDE method, formalising the creation of a scorecard with which teams can evaluate project briefs. By identifying the critical, measurable contributing elements for each of the influential factors, these factors have an improved definition and can be more easily evaluated. This scorecard allows for projects to be more readily evaluated based on factor scores and the scores of each contributing element. The scorecard also includes points spread for each factor to assign a score - the assessed values of each element and a total and its corresponding location within a spread dictates the factor's level.

\subsection{Research Question}

From this review, it is clear that estimating design effort for product design is challenge that is essential to resolve to improve the survivability of (typically small) product design consultancies. Many approaches found in the literature consider various influential factors when developing methods to estimate design effort. Many of these approaches require large data sets of past project performance, which enables estimates to be quickly produced, but limits their suitability to product design consultancies. In lieu of data analysis-based prediction models, many product design consultancies use tacit knowledge and experience based estimation. Although this approach can be accurate, it is time consuming and can be based on "hunches" which are difficult for others to clearly interpret. Therefore this paper poses to answer the research question:

RQ1: How can a design effort estimation tool be developed that creates quick and accurate estimates, like those of an analytical based model, with the tacit knowledge and experience of designers, who are experts of their own practice?

This paper discusses the development of a resource forecasting tool development approach a la the DF method, following the CoFIDE method, adopting its changes and improvements and incorporating the creation of a project brief scorecard from the CPBS method.

\section{DATALESS DESIGN EFFORT FORECASTING - A PROPOSED METHOD}

This section discusses a proposed new method for creating a design effort needs forecasting tool for product design agencies.

\subsection{Application of method}

This proposed method is intended to be used by entire product design consultancy team. There are a number of benefits to working collaboratively with whole teams, rather than a subsection, such as the team managers, as the DF method does. By engaging with the whole design team, this method capitalises on the diverse knowledge and experience of all its members. Additionally, this method empowers design teams to have an open discussion about the plethora of factors which may influence their projects, fostering debate and enabling each team member to have, and share, their opinions. As this method captures and models each member's unique perspective of the design space, enabling not only for the creation of an estimation tool, but enables direct comparisons between each team members' perspectives of the factors that influence their shared design space. An additional focus of this method is to produce method outputs that are visual. This allows for quicker digestion and comprehension of information, enabling for quicker comparison and decision making based on the information portrayed visually.

\subsection{Proposed methodology}

This proposed method should be conducted with all permanent members of a design team, this includes any director-level member and graduates. This can be opened up to contract workers (i.e. freelancers) if they have worked with the team for an adequate length of time. Each phase of this method is outlined in Figure 3 and will be discussed in the corresponding subsequent sections. 


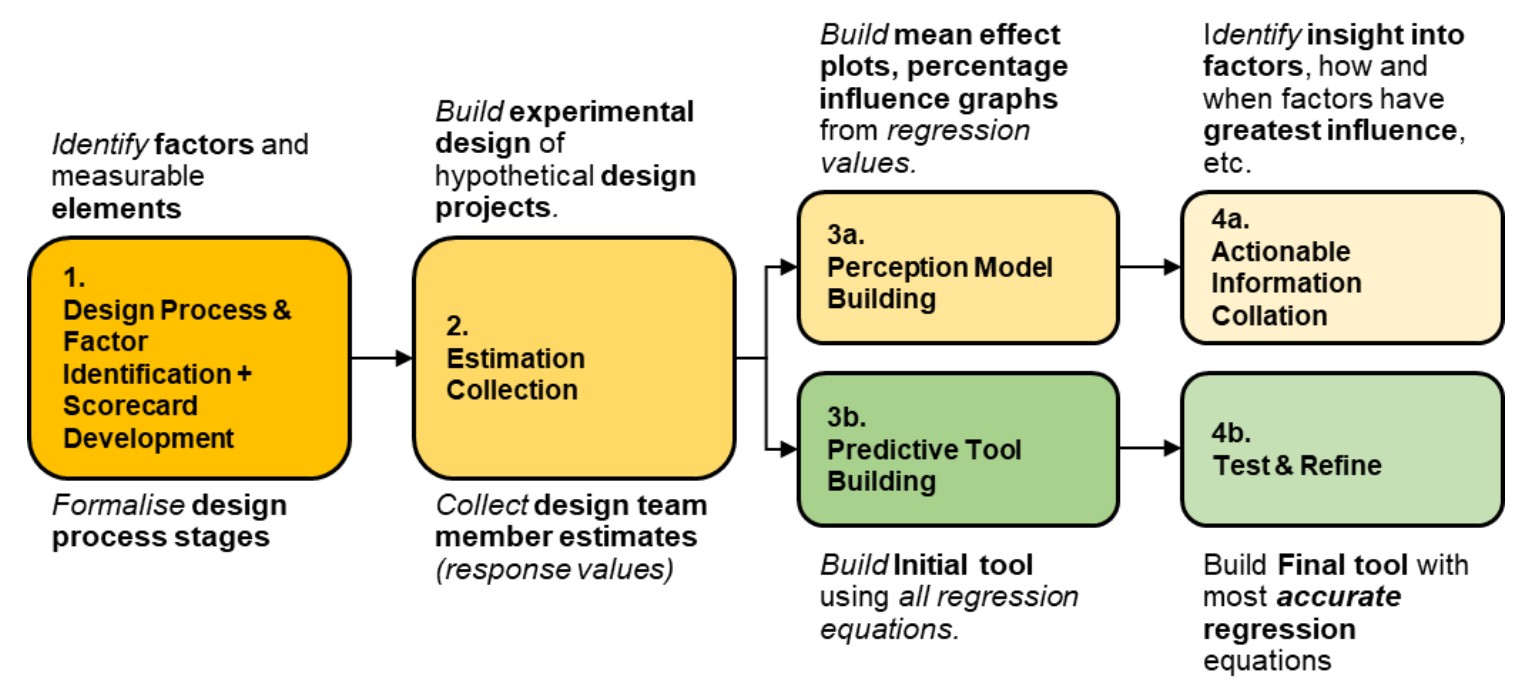

Figure 3. A proposed dataless design effort estimation tool creation method

\subsubsection{Steps 1 \& 2: design process \& factor identification \& estimation collection}

These initial steps follow the CoFIDE approach (Holliman, Thomson, Hird, et al., 2020). The design team clarifies their design process, establishing each discrete phase of a project. The team further identifies those factors, or their elements, which influence design effort levels through a typical brainstorming activity. These are collated into formal factors, generated from collated measurable elements. Once grouped and voted for, those with the greatest influence are voted for and their elements are gathered, with which a scorecard is created. A four-level ranges is defined for each element, including possible minimum and maximum values for each. These factors and the minimum and maximum levels are used to construct an experimental design containing a series of hypothetical design projects. Estimates (response values) for each project and their stages are made individually by each team members and the results are collated.

\subsubsection{3a perception model building \& $3 b$ predictive tool building}

Regression analysis is applied to the response values, producing a set of regression equations for each team member, and project phase. From this analysis, a number of graphical models can be made, shown in Figure 4. These models are deliberately visual as part of the aim to maintain a visual output to this proposed method.
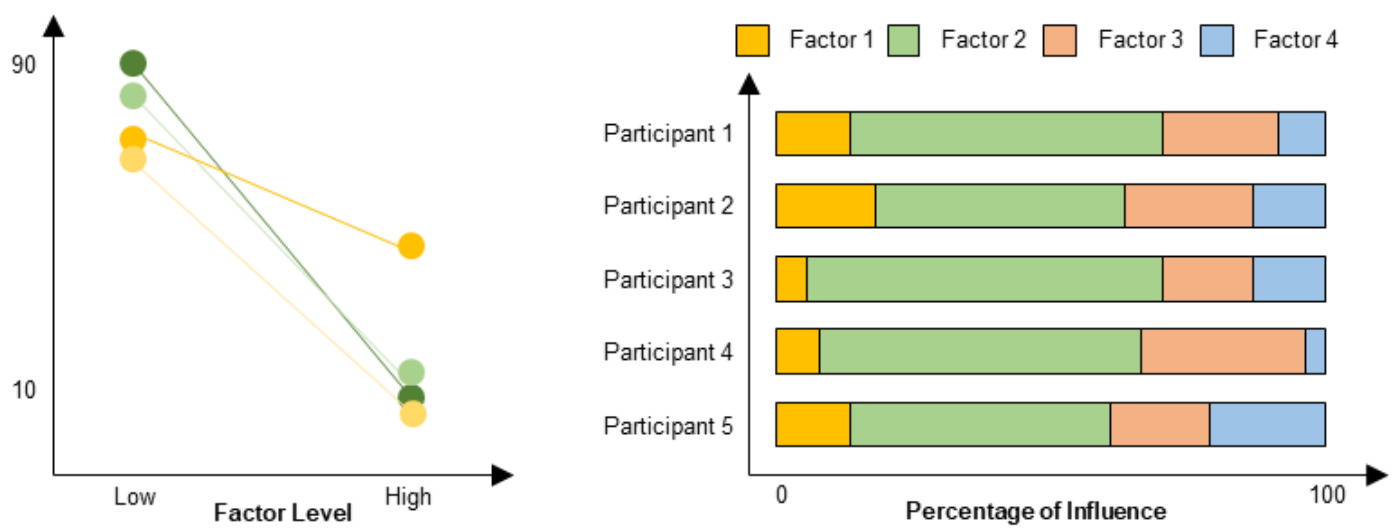

Figure 4. Example mean effect plots (left) and percentage influence graphs (right)

The coefficient values of the regression equations can be used to create percentage influence graphs (shown on the right of Figure 4) to show which factor has the greatest influence. In this example the percentage influence graph (a linear pie chart) illustrates that factor 2 (green) has the greatest percentage of influence over design effort needs for that given project phase. This insight can be quickly understood due to the visual and colour-coded approach. 
The mean effect values (shown on the left of Figure 4) can be used to create mean effect plots, which can model the behaviour of factors over the course of a design project. In these example, the mean effect plots illustrate that a factor's influence is greater when it is at a low level, than at a high;

The regression equations can also be used to create an initial estimation tool within a spreadsheet, an example of which is shown in Figure 5. In the input section (in green), each factor and their corresponding elements are arranged and a check-box style marker can be made to indicate the element level. The element levels are totalled and a factor level is determined by the score ranges (as discussed previously. The factor level values control their corresponding value for each regression equation. The calculated output of each regression equation is displayed in the corresponding cell of the output (in yellow) representing the estimated design effort for the corresponding phase of a project.

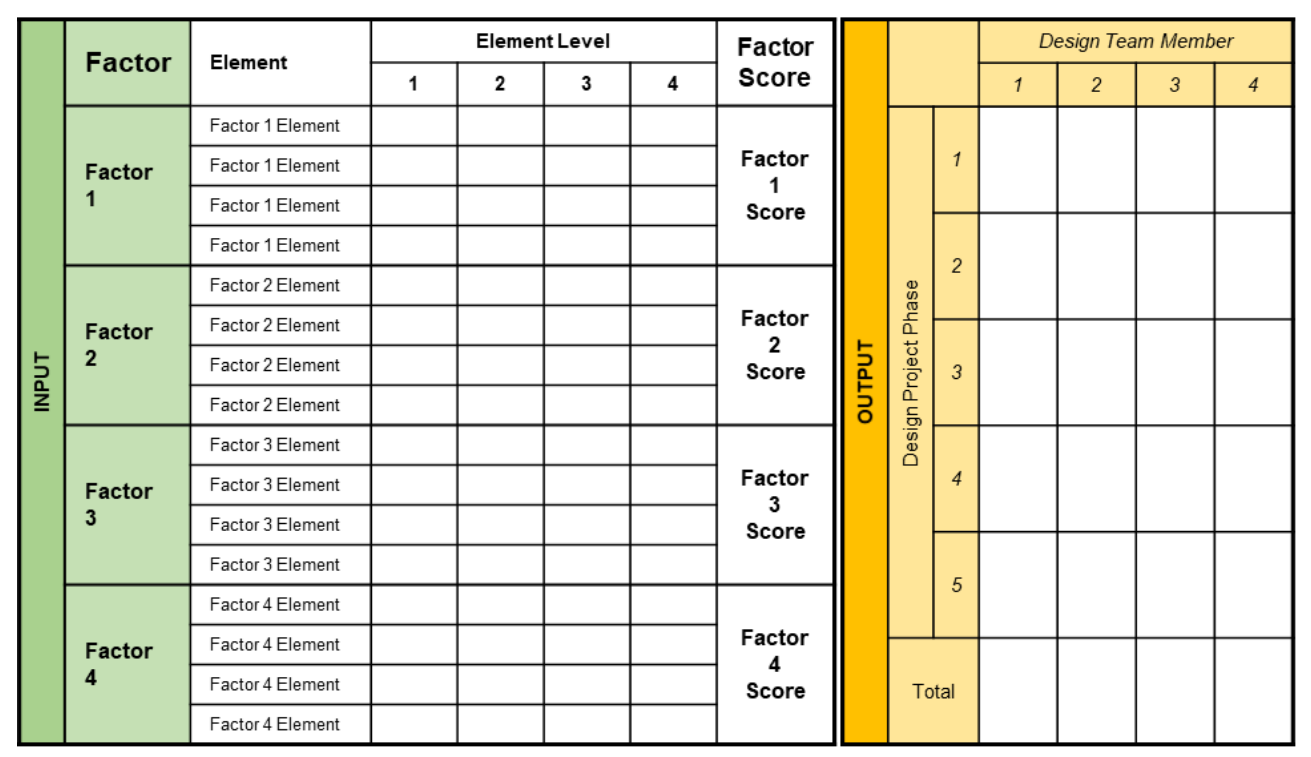

Figure 5. Initial predictive tool for evaluation

\subsubsection{4b. test \& refine}

Using a collection of past project briefs and performance data, the design team can use the input of the evaluation tool to assign factor levels for each, recording their output. These evaluations and their output can then be used to identify the regression equations for each project phase that are most accurate. These may not always be from the same member of the design team, as the experience each team member has may differ between phases. Once the most accurate regression equations have been identified, a final estimation tool can be created in a spreadsheet, using said equations only. An example of this tool is shown in Figure 6.

\subsection{Proposed method analysis}

This proposed method offers a tool which enables product design teams to estimate design effort for their projects without the need for large data sets of past project performances, a clear advantage to many other tool creation approaches. In addition, this method works collaboratively with all members of the design team, ensuring that no team member's perceptions, experience or tacit knowledge is overlooked, and that active discussion and debate can be fostered, providing valuable insight into the design space. Furthermore, this proposed method provides the design team with models of each factor, illustrating how their influence changes over the duration of a project.

\section{FUTURE WORK}

In order to fully determine how useful the insight offered by this method, and how accurate the model's estimates can be, case studies should be conducted with a range of product design agencies of various sizes and experiences. Doing so globally may enable for the identification of which factors are perceived to have the most influence globally, potentially developing a de facto list of the most influential factors of design effort levels in product design consultancy projects. 


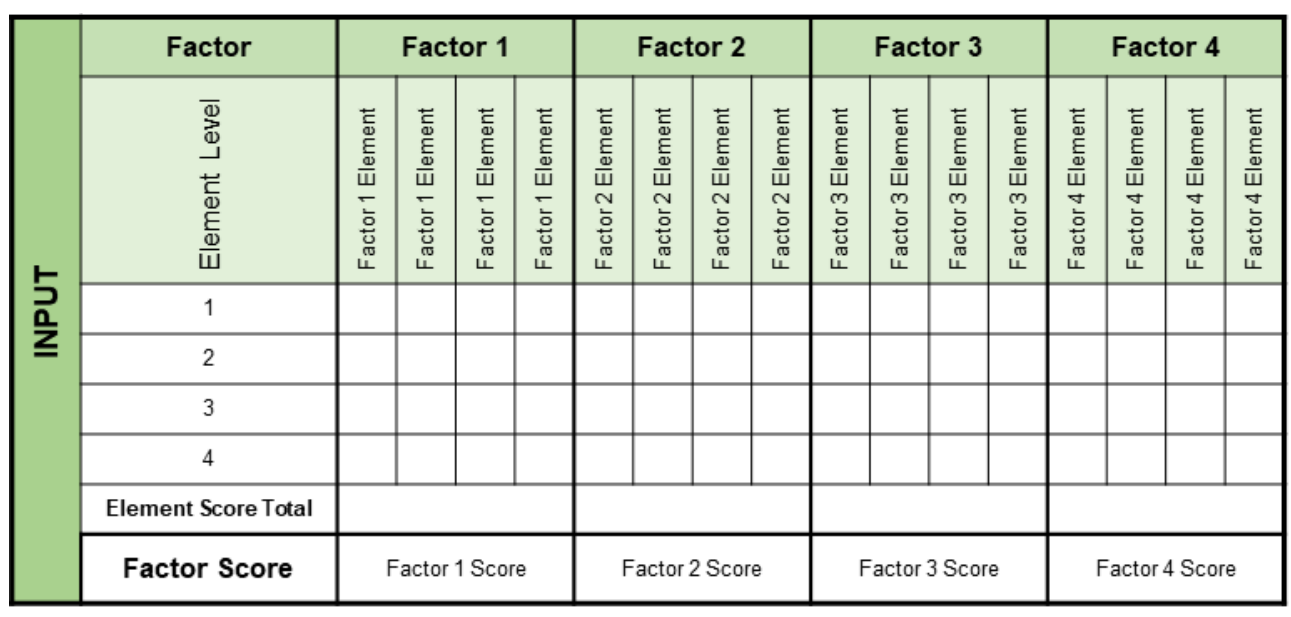

\begin{tabular}{|c|c|c|c|c|c|c|}
\hline \multirow{2}{*}{ 与 } & \multicolumn{7}{|c|}{ Design Project Phase } \\
\cline { 2 - 7 } & 1 & 2 & 3 & 4 & 5 & Total \\
\cline { 2 - 7 } & $\begin{array}{c}\text { Estimate } \\
\text { Value }\end{array}$ & $\begin{array}{c}\text { Estimate } \\
\text { Value }\end{array}$ & $\begin{array}{c}\text { Estimate } \\
\text { Value }\end{array}$ & $\begin{array}{c}\text { Estimate } \\
\text { Value }\end{array}$ & $\begin{array}{c}\text { Estimate } \\
\text { Value }\end{array}$ & $\begin{array}{c}\text { Total } \\
\begin{array}{c}\text { Estimate } \\
\text { Value }\end{array}\end{array}$ \\
\hline
\end{tabular}

Figure 6. Final predictive tool for deployment

\subsection{Post-deployment evaluation}

A formalised protocol for evaluating the estimating tool once it has been deployed should be considered. This would allow for potential refinements to the regression equations, etc. to improve the accuracy of the estimation. Although the regression equations will be tested and selected based on a number of past projects, there will likely be further improvements and adjustments that could be observed only once the tool was being used for live projects.

\subsection{Method repetition frequency}

By observing a number of industrial case studies, it may be possible to determine a suitable schedule for conducting repeats to the tool building process. This could be necessary if the insight that is offered through the design space modelling is utilised to make improvements. A re-assessment of the design space and its influencing factors would allow the tool to remain accurate.

\subsection{Identification of add-ons to predictive tool}

A further avenue for a range of potential extensions of the predictive tool would be to add functionality based on output of a prediction. This could include recommendation engines and further question generation. Once case studies are underway, consultation with product design consultancy partners would allow for customisation.

\section{CONCLUSION}

Using tacit knowledge and experience to inform project resource estimates, including design effort, is a successful approach. However this is problematic, as in order to take advantage of this knowledge, a designer must spend time on planning, rather than designing. This can eat into a product design consultancy's "bottom line". This a particular issue as the majority of product design agencies in the UK are small businesses, with a $40 \%$ failure rate.

This paper considers the following research question:

RQ1: How can a design effort estimation tool be developed that creates quick and accurate estimates, like those of an analytical based model, with the tacit knowledge and experience of designers, who are experts of their own practice? 
This paper addresses this research question by proposing a novel method for producing a design effort estimation tool for product design agencies. By capturing the tacit knowledge and experience that designers have of the design space, it is possible to produce a tool that will quickly generate design effort requirements predictions for new projects. These predictions can not only aid project management, but also project costing. Furthermore, as the tacit knowledge and experience is captured, the designers from which that knowledge originated can be prevented from stopping design activities to contribute to project planning activities.

In addition, this proposed method provides design teams with a range of insight into the design space and the factors that influence design effort needs for their projects. Through the use of mean effect plots and percentage influence graphs, the most influential factors of design effort demands are modelled, providing critical detail into which phases of a project are influenced the most by each factor.

Fundamentally this proposed method has the potential to save product design agencies time and money, preventing the possible wastage of each.

\section{REFERENCES}

Bashir, H.A. and Thomson, V. (2001a), “An analogy-based model for estimating design effort”, Design Studies, Vol. 22 No. 2, pp. 157-167.

Bashir, H.A. and Thomson, V. (2001b), "Models for estimating design effort and time”, Design Studies, Vol. 22 No. 2, pp. 141-155.

Benedetto, H., Bernardes, M.M. e S. and Vieira, D. (2018), "Proposed framework for estimating effort in design projects", International Journal of Managing Projects in Business, Emerald, Vol. 11 No. 2, pp. 257-274.

Benton, S., Miller, S. and Reid, S. (2018), The Design Economy 2018: The State of Design in the UK, available at: https://www.designcouncil.org.uk/sites/default/files/asset/document/Design_Economy_2018.pdf.

Brauers, J. and Weber, M. (1988), "A new method of scenario analysis for strategic planning”, Journal of Forecasting, John Wiley \& Sons, Ltd., Vol. 7 No. 1, pp. 31-47.

Chalupnik, M.J., Wynn, D.C. and Clarkson, P.J. (2009), “Approaches to Mitigate the Impact of Uncertainty in Development Processes", DS 58-1: Proceedings of ICED 09, the 17th International Conference on Engineering Design, Vol. 1, Design Processes2, The Design Society, Palo Alto, CA, USA, pp. 459-470.

Cohn, M. (2005), Agile Estimating and Planning, Pearson Education Ltd., London.

Dong, C., Horinouchi, T., Nomaguchi, Y. and Fujita, K. (2014), "Design Project Planning Method With Task Option Model and Two-Level Multi-Objective Optimization".

Eckert, C.M. and Clarkson, P.J. (2010), "Planning development processes for complex products", Research in Engineering Design, Vol. 21 No. 3, pp. 153-171.

Eppinger, S.D., Whitney, D.E., Smith, R.P. and Gebala, D.A. (1994), “A model-based method for organizing tasks in product development", Research in Engineering Design, Vol. 6 No. 1, pp. 1-13.

Fisher, R.A. (1949), The Design of Experiments, 5th ed., Oliver and Boyd, Edinburgh.

Griffin, A. (1993), "Metrics for measuring product development cycle time", Journal of Product Innovation Management, Vol. 10 No. 2, pp. 112-125.

Harfield, S. (2007), “On design 'problematization': Theorising differences in designed outcomes", Design Studies, Vol. 28 No. 2, pp. 159-173.

Hird, A. (2012), A Systems Approach to Resource Planning in New Product Development, edited by University of Strathclyde. Dept. of Design, M. and E.M., Thesis [Eng. D] -- University of Strathclyde, 2012.

Holliman, A.F., Thomson, A. and Hird, A. (2020), "Collaborative project brief scorecard method: Evaluating product design projects to aid design effort estimation", in Marjanovic, D., Storga, M., Pavkovic, N. and Bojcetic, N. (Eds.), DS 102: Proceedings of the DESIGN 2020 16th International Design Conference, The Design Society, pp. 1445-1454.

Holliman, A.F., Thomson, A., Hird, A. and Wilson, N. (2020), "What's taking so long? A collaborative method of collecting designers' insight into what factors increase design effort levels in projects", Artificial Intelligence for Engineering Design, Analysis and Manufacturing, Cambridge University Press, pp. 1-22.

Jack, H. (2013), "Chapter 6 - Planning and Managing Projects BT - Engineering Design, Planning, and Management", Academic Press, Boston, pp. 215-244.

Jaifer, R., Beauregard, Y. and Bhuiyan, N. (2020), "New Framework For Effort And Time Drivers In Aerospace Product Development Projects", Engineering Management Journal, Taylor \& Francis, pp. 1-20.

Jonassen, D.H. (2000), "Toward a design theory of problem solving”, Educational Technology Research and Development, Vol. 48 No. 4, pp. 63-85. 
Lindemann, U., Maurer, M. and Braun, T. (2009), Structural Complexity Management: An Approach for the Field of Product Design, Structural Complexity Management: An Approach for the Field of Product Design, TU München, Lehrstuhl für Produktentwicklung, Boltzmannstr. 15, 85748 Garching, Germany, available at:https://doi.org/10.1007/978-3-540-87889-6.

Luck, R. (2013), “Articulating (mis)understanding across design discipline interfaces at a design team meeting”, Artificial Intelligence for Engineering Design, Analysis and Manufacturing, Cambridge University Press, Vol. 27 No. 2, pp. 155-166.

Maurer, M. (2017), Complexity Management in Engineering Design - a Primer, Complexity Management in Engineering Design - a Primer, Technische Universität München, Garching, Bayern, Germany, available at:https://doi.org/10.1007/978-3-662-53448-9.

Musès, C. (2000), "Simplifying complexity: The greatest present challenge to management and government", Kybernetes, Emerald, Vol. 29 No. 5/6, pp. 612-637.

O’Donovan, B., Eckert, C., Clarkson, J. and Browning, T.R. (2005), “Design planning and modelling”, in Clarkson, J. and Eckert, C. (Eds.), Design Process Improvement: A Review of Current Practice, Springer London, London, pp. 60-87.

Office of National Statistics. (2018), Business Demography, UK: 2017, available at: https://www.ons.gov.uk/businessindustryandtrade/business/activitysizeandlocation/bulletins/businessdemog raphy/2018.

Pich, M.T., Loch, C.H. and Meyer, A. De. (2002), “On Uncertainty, Ambiguity, and Complexity in Project Management”, Management Science, INFORMS, Vol. 48 No. 8, pp. 1008-1023.

Pollmanns, J., Hohnen, T. and Feldhusen, J. (2013), “An Information Model of the Design Process for the Estimation of Product Development Effort BT - Smart Product Engineering”, in Abramovici, M. and Stark, R. (Eds.), , Springer Berlin Heidelberg, Berlin, Heidelberg, pp. 885-894.

Salam, A. and Bhuiyan, N. (2016), "Estimating design effort using parametric models: A case study at Pratt \& Whitney Canada", Concurrent Engineering, SAGE Publications Ltd STM, Vol. 24 No. 2, pp. 129-138.

Serrat, J., Lumbreras, F. and López, A.M. (2013), "Cost estimation of custom hoses from STL files and CAD drawings", Computers in Industry, Vol. 64 No. 3, pp. 299-309.

Shafiee, S., Herbert-Hansen, Z.N.L., Hvam, L., Haug, A., Bonev, M. and Mortensen, N.H. (2019), "Development of a Design-Time Estimation Model for Complex Engineering Processes", Advances in Transdisciplinary Engineering, Vol. 10, pp. 301-310.

Shah, J.J. and Runger, G. (2013), "What is in a name? On the misuse of information theoretic dispersion measures as design complexity metrics", Journal of Engineering Design, Taylor \& Francis, Vol. 24 No. 9 , pp. 662-680.

Shang, Z.-G. and Yan, H.-S. (2016), "Product Design Time Forecasting by Kernel-Based Regression with Gaussian Distribution Weights”, Entropy, Vol. 18 No. 6, pp. 231-248.

Suh, N.P. (1999), “A Theory of Complexity, Periodicity and the Design Axioms”, Research in Engineering Design, Vol. 11 No. 2, pp. 116-132.

Tatikonda, M. V and Rosenthal, S.R. (2000), "Technology novelty, project complexity, and product development project execution success: a deeper look at task uncertainty in product innovation", IEEE Transactions on Engineering Management, Vol. 47 No. 1, pp. 74-87.

Wang, Z., Tong, S. and Huang, L. (2015), "Research on the time prediction model of product variant design", 2015 IEEE International Conference on Mechatronics and Automation (ICMA), IEEE, pp. 572-576.

Whitney, D.E. (1990), “Designing the design process”, Research in Engineering Design, Vol. 2 No. 1, pp. 3-13. 